\title{
Cocoa flavonoids improve insulin signalling and modulate glucose production via AKT and AMPK in HepG2 cells
}

Isabel Cordero-Herrera ${ }^{1}$, María Angeles Martín ${ }^{1,2}$, Laura Bravo ${ }^{1}$, Luis Goya $^{1}$ and Sonia Ramos ${ }^{1, *}$

${ }^{1}$ Department of Metabolism and Nutrition

Institute of Food Science and Technology and Nutrition (ICTAN)

Consejo Superior de Investigaciones Científicas (CSIC)

José Antonio Novais 10

Ciudad Universitaria, 28040, Madrid

Spain

Phone: +34.91.544.56.07

Fax: +34.91.549.36.27

${ }^{2}$ Centro de Investigación Biomédica en Red de Diabetes y Enfermedades Metabólicas Asociadas (CIBERDEM), ISCIII, Spain.

* Corresponding author: e-mail: s.ramos@ictan.csic.es

Abbreviations used: AKT/PKB, protein kinase B; AMPK, 5'-AMP-activated protein kinase; BrdU, 5-bromo-2'-deoxyuridine; CaMMK, $\mathrm{Ca}^{2+} /$ calmodulin-dependent protein kinase kinase; CPE, cocoa phenolic extract; EC, (-)-epicatechin; EGCG, epigallocatechin gallate; FBS, fetal bovine serum; FOXO1, forkhead box protein O1; GLUT, glucose transporter; GS, glycogen synthase; GSK-3, glycogen synthase kinase3; G6Pase, glucose-6-phosphatase; IR, insulin receptor; IRS, insulin receptor substrate; LKB1, liver kinase B1; PPAR, peroxisome proliferator-activated receptor; PEPCK, phosphoenolpyruvate carboxykinase; PI3K, phosphatidylinositol-3-kinase.

Keywords: Cocoa, Epicatechin, Glucose production, Insulin signalling pathway, HepG2 cells. 


\begin{abstract}
Scope: Cocoa and (-)-epicatechin (EC), a main cocoa flavanol, have been suggested to exert beneficial effects in diabetes, but the mechanism for their insulin-like effects remains unknown. In this study, the modulation of insulin signalling by EC and a cocoa phenolic extract (CPE) on hepatic HepG2 cells was investigated by analysing key proteins of the insulin pathways, namely insulin receptor (IR), insulin receptor substrate (IRS)-1 and 2, PI3K/AKT and 5'-AMP-activated protein kinase (AMPK), as well as the levels of the glucose transporter GLUT-2 and the hepatic glucose production.
\end{abstract}

Methods and results: EC and CPE enhanced the tyrosine phosphorylation and total IR, IRS-1 and IRS-2 levels and activated the PI3K/AKT pathway and AMPK in HepG2 cells. CPE also enhanced the levels of GLUT-2. Interestingly, EC and CPE modulated the expression of phosphoenolpyruvate carboxykinase, a key protein involved in the gluconeogenesis, leading to a diminished glucose production. In addition, EC- and CPE-regulated hepatic gluconeogenesis was prevented by the blockage of AKT and AMPK.

Conclusion: Our data suggest that EC and CPE strengthen the insulin signalling by activating key proteins of that pathway and regulating glucose production through AKT and AMPK modulation in HepG2 cells. 


\section{Introduction}

Diabetes is one of the most common chronic diseases in nearly all countries, and it is continuing to be an increasing international health burden [1]. Current medications are not adequately effective in maintaining long-term glycemic control in most patients. Therefore, there is an urgent need to continue working on the prevention and control of diabetes. In this regard, a promising approach is the employ of the natural compounds with insulin-like activity, which have been proposed as potential therapeutic agents in the prevention and/or treatment of this disease [2].

The liver has an important role in the control of the whole body metabolism of energy nutrients. In diabetes, the insulin target tissues are damaged, which aggravates the ability of insulin to trigger downstream metabolic actions resulting in insulin resistance. In this regard, one of the hallmarks of diabetes is the alteration of the hepatic metabolism: the liver is not able to control the glucose homeostasis, which is one of the causes for the hyperglycemia, and there is a miss-regulation of the insulin pathway in this organ [3].

Insulin signal transduction is initiated when insulin binds to the insulin receptor (IR), which leads to the stimulation of several intracellular protein substrates including insulin receptor substrate (IRS)-1 and IRS-2. This triggers the phosphatidylinositol-3kinase $(\mathrm{PI} 3 \mathrm{~K})$ pathway that stimulates AKT and leads to the inhibition of glycogen synthase kinase-3 (GSK-3) by phosphorylation, which subsequently phosphorylates and inactivates glycogen synthase (GS), and conducts to the modulation of other proteins necessary for the acute metabolic effects of insulin [3]. In addition, in the hepatocyte AKT might phosphorylate the transcription factor forkhead box protein O1 (FOXO1), restraining the expression of phosphoenolpyruvate carboxykinase (PEPCK) and glucose-6-phosphatase (G6Pase), and inhibiting the gluconeogenesis [3]. 5'-AMP- 
activated protein kinase (AMPK) also constitutes a central regulator of the cellular metabolism, able to suppress the hepatic gluconeogenesis [4]; in fact numerous drugs that are in clinical use for treatment of type 2 diabetes activate AMPK $[4,5]$.

(-)-Epicatechin (EC) is one of the most abundant flavonoids in human diet, being present in high concentrations in grapes, cocoa, tea, and many other fruit and vegetables $[6,7]$. Different studies have shown that EC is able to interfere with the oxidative/antioxidative potential of hepatic cells $[6,8]$, induces survival/proliferation pathways [8-10], exerts insulin-like activities [11], and improves insulin sensitivity [12], blood glucose levels [13] and parameters related to the inflammation in cardiovascular disease and diabetes $[12,14,15]$. Similarly, dark chocolate or cocoa, which are widely consumed [16] and are a rich source of flavonoids, especially (-)-epicatechin [6], have been reported to protect against carcinogenesis [7, 17], improve the allergy process [18], cardiovascular status $[16,19,20]$, insulin sensitivity and hyperglycemia $[19,21]$ in humans and experimental animals. However, the precise mechanism for the preventive activities of EC and cocoa related to glucose metabolism and insulin signalling in the liver remains largely unknown.

The present work evaluates the effects of EC and a cocoa phenolic extract (CPE) on insulin signalling pathways and glucose production in HepG2 cells. The study demonstrates that EC and CPE have insulinomimetic activities in the human hepatic HepG2 cells, as EC and CPE enhanced the tyrosine phosphorylation and total IR, IRS-1 and IRS-2 levels, which was associated to an activation of the PI3K/AKT pathway and AMPK. We have also found that AKT and AMPK are required to modulate the hepatic glucose production. 


\section{Materials and methods}

\subsection{Materials and chemicals}

(-)-EC (>95\% of purity), Compound C (6-[4-(2-Piperidin-1-ylethoxy)phenyl]-3-pyridin4-ylpyrazolo[1,5-a]pyrimidine), LY294002 (2-(4-morpholinyl)-8-phenyl-1(4H)benzopyran-4-one hydrochloride), anti-mouse IgG-agarose, sodium lactate, sodium pyruvate, gentamicin, penicillin $G$ and streptomycin were purchased from Sigma Chemical (Madrid, Spain). Cell proliferation ELISA BrdU (colorimetric) assay kit was from Roche Diagnostics (Barcelona, Spain). Anti-AKT and anti-phospho-Ser473-AKT detecting levels of phospho- and total AKT 1-3, anti-AMPK and anti-phospho-Thr172AMPK, as well as anti-GSK3 $\alpha / \beta$ and anti-phospho-GSK3 $\alpha / \beta$ recognizing phosphorylated Ser21/9 of GSK3, anti-GS and anti-phospho-GS recognizing phosphorylated Ser641 of GS, anti-IRS-2 and anti- $\beta$-actin were obtained from Cell Signalling Technology (Izasa, Madrid, Spain). Anti-IR $\beta$, anti-PEPCK and anti-Tyr(P) (PY20) were purchased from Santa Cruz (sc-711, sc-32879 and sc-508, respectively, Qimigen, Madrid, Spain). Anti-IRS-1 and anti-GLUT-2 were from Millipore (Madrid, Spain). Materials and chemicals for electrophoresis were from BioRad (BioRad Laboratories S.A., Madrid, Spain). Cell culture dishes and cell culture medium were from Falcon (Cajal, Madrid, Spain) and Lonza (Madrid, Spain), respectively.

\subsection{Cocoa polyphenol extraction}

Natural Forastero cocoa powder (Nutrexpa, Barcelona, Spain) was used for this study. Soluble polyphenols were extracted by sequentially washing $1 \mathrm{~g}$ of sample with $40 \mathrm{~mL}$ of $16 \mathrm{mM}$ hydrochloric acid in $50 \%$ aqueous methanol $(50: 50, \mathrm{v} / \mathrm{v}, 1 \mathrm{~h}$ at room temperature, constant shaking) and $40 \mathrm{~mL}$ of acetone:water $(70: 30, \mathrm{v} / \mathrm{v}, 1 \mathrm{~h}$ at room temperature, constant shaking). After centrifugation (15 min, $3000 \mathrm{~g}$ ), supernatants 
from each extraction step were combined and made up to $100 \mathrm{~mL}$. The desiccated extract was dissolved in distilled water and kept frozen until assay. A detailed description of this cocoa polyphenol extract (CPE) is given elsewhere $[6,22]$. Accordingly, the amount of EC and polyphenols present in the CPE were 383.5 $\mathrm{mg} / 100 \mathrm{~g}$ (determined by LC-MS) and $2 \mathrm{~g} / 100 \mathrm{~g}$ on dry matter basis (determined by Folin-Ciocalteu) [6]. Concentrations of EC in tested doses of CPE range from $13.2 \mathrm{nM}$ (in the dose of $1 \mu \mathrm{g} \mathrm{CPE} / \mathrm{mL}$ ) to $132 \mathrm{nM}$ (in that of $10 \mu \mathrm{g} \mathrm{CPE} / \mathrm{mL}$ ) [6].

\subsection{Cell culture and treatments}

Human HepG2 cells were grown in DMEM-F12 medium supplemented with $2.5 \%$ foetal bovine serum (FBS) and the following antibiotics: gentamicin, penicillin and streptomycin $(50 \mathrm{mg} / \mathrm{L})$. Cells were maintained at $37^{\circ} \mathrm{C}$ in a humidified atmosphere of $5 \% \mathrm{CO}_{2}$. One day after plating, the medium was changed to DMEM containing $5.5 \mathrm{mM}$ D-glucose, $2 \mathrm{mM}$ glutamine and FBS, and the culture was continued. Subsequently, the experimental treatment was carried out for the indicated periods with various concentrations of EC or CPE in serum-free media containing $5.5 \mathrm{mM}$ D-glucose, $2 \mathrm{mM}$ glutamine for $24 \mathrm{~h}$.

Cells were treated with different concentrations of EC (1-20 $\mu \mathrm{M})$ or CPE $(1-20 \mu \mathrm{g} / \mathrm{mL})$ diluted in serum-free culture medium during $24 \mathrm{~h}$. In the experiments with the pharmacological inhibitors, cells were preincubated with $25 \mu \mathrm{M}$ LY294002 or $40 \mu \mathrm{M}$ Compound $\mathrm{C}$ for $1 \mathrm{~h}$ prior to $24 \mathrm{~h}$ of $\mathrm{EC}$ or CPE treatment.

\subsection{Cell viability assay}

Cell viability was determined by using the crystal violet assay [8]. HepG2 cells were seeded at low density $\left(10^{4}\right.$ cells per well counted in a Neubauer chamber $)$ in $96-$ well 
plates, grown for $20 \mathrm{~h}$ and incubated with crystal violet $(0.2 \%$ in ethanol) for $20 \mathrm{~min}$. Plates were rinsed with water, allowed to dry, and $1 \%$ sodium dodecylsulfate added. The absorbance of each well was measured using a microplate reader at $570 \mathrm{~nm}$.

\subsection{Cell proliferation assay (5-bromo-2'-deoxyuridine assay, BrdU)}

A colorimetric immunoassay (ELISA) was used for the quantification of cell proliferation [8]. This method is based on the measurement of BrdU incorporation into genomic DNA during DNA synthesis of proliferating cells. HepG2 cells were seeded $\left(10^{4}\right.$ cells per well counted in a Neubauer chamber) in 96-well plates, grown $20 \mathrm{~h}$ and labelled by the addition of BrdU for $4 \mathrm{~h}$. Then the anti-BrdU antibody was added and the immune complexes were quantified by measuring the absorbance at $620 \mathrm{~nm}$ in a microplate reader.

\subsection{Preparation of cell lysates}

Cells were lysed at $4^{\circ} \mathrm{C}$ in a buffer containing $25 \mathrm{mM}$ HEPES (pH 7.5), 0.3 M NaCl, 1.5 $\mathrm{mM} \mathrm{MgCl}_{2}, 0.2 \mathrm{mM}$ EDTA, $0.5 \mathrm{mM}$ dithiothreitol, 0.1\% Trition X-100, $200 \mathrm{mM} \beta$ glycerolphosphate, $\quad 0.1 \quad \mathrm{mM} \quad \mathrm{Na}_{3} \mathrm{VO}_{4}, \quad 2 \mu \mathrm{g} / \mathrm{mL}$ leupeptin and $1 \mathrm{mM}$ phenylmethylsulfonyl fluoride. The supernatants were collected, assayed for protein concentration by using the Bio-Rad (Bio-Rad, Madrid, Spain) protein assay kit according to the manufacture's specifications, aliquoted and stored at $-80^{\circ} \mathrm{C}$ until used for immunoprecipitation and/or Western blot analyses.

\subsection{Immunoprecipitation}

Protein extracts containing $200 \mu \mathrm{g}$ of protein were immunoprecipitated overnight at $4^{\circ} \mathrm{C}$ with gentle rotation in the presence of 2-5 $\mu \mathrm{g}$ of anti-Tyr(P) (PY20) antibody, followed 
by the addition of anti-mouse IgG-agarose. After mixing for $2 \mathrm{~h}$, the pellets were collected by centrifugation, and the supernatants were discarded. Then the pellets were washed and saved for Western blot analyses.

\subsection{Western blot analysis}

Equal amounts of proteins were separated by SDS-polyacrylamide gel electrophoresis and transferred to polyvinylidene difluoride filters (Bio-Rad, Madrid, Spain). Membranes were probed with the corresponding primary antibody followed by incubation with peroxide-conjugated anti-rabbit (GE Healthcare, Madrid, Spain) or antimouse (Sigma, Madrid, Spain) immunoglobulin. Blots were developed with the ECL system (GE Healthcare, Madrid, Spain). Normalization of Western blot was ensured by $\beta$-actin and bands were quantified using a scanner and accompanying software.

\subsection{Glucose production assay}

HepG2 cells were seeded in 24-well plates $\left(2 \times 10^{5}\right.$ cells per well counted in a Neubauer chamber) and treated in serum-free DMEM with $10 \mu \mathrm{M}$ EC or $1 \mu \mathrm{g} / \mathrm{mL}$ CPE for $24 \mathrm{~h}$. The medium was then replaced with glucose production buffer consisting of glucosefree DMEM (pH 7.4), without phenol red (Invitrogen, Madrid, Spain), supplemented with $20 \mathrm{mM}$ sodium lactate and $2 \mathrm{mM}$ sodium pyruvate, as previously described [23, 24]. After a 3-h incubation, medium was collected and glucose concentration measured with a colorimetric glucose assay kit (Sigma, Madrid, Spain). The readings were then normalized to the total protein content determined from the whole-cell lysates.

\subsection{Statistics}


Prior to statistical analysis, data were tested for homogeneity of variances by the test of Levene; for multiple comparisons, one-way ANOVA was followed by the Bonferroni test when variances were homogeneous or by the Tamhane test when variances were not homogeneous. $P<0.05$ was considered significant. A SPSS version 19.0 program has been used. 


\section{Results}

\subsection{Cell viability and proliferation}

To determine the potential effects on cell viability and proliferation of EC and CPE in a human hepatic cell line (HepG2), cells were exposed to a range of concentrations (0-20 $\mu \mathrm{M}$ and $0-20 \mu \mathrm{g} / \mathrm{mL}$, respectively) for $24 \mathrm{~h}$.

Treatment of HepG2 cells for $24 \mathrm{~h}$ with EC or CPE did not evoke changes in cell viability, as determined by the crystal violet assay, indicating that the concentrations selected for the study did not damage cell integrity during the period of incubation (Table 1). Similarly, treatment with EC or CPE did not affect cell growth, indicating no impairment of cell proliferative machinery and preservation of a regular cell cycle (Table 1). Since none of the tested doses induced cell toxicity, the lowest and realistic range of concentrations was selected for further studies [6, 22].

\subsection{Effects of EC and CPE on tyrosine phosphorylation and protein levels of IR and its substrates IRS-1 and IRS-2}

The modulation of IR and its downstream substrates IRS-1 and IRS-2 is essential for recruiting and activating downstream pathways [25]. In fact, in hepatic insulin resistance the insulin-stimulated-IR and IRS tyrosine phosphorylation is defective and results in reduced IRS-associated PI3K activities [3]. To test the effect of EC and CPE on tyrosine phosphorylation and total levels of IR and its substrates, HepG2 cells were exposed for $24 \mathrm{~h}$ to various concentrations of these substances.

As shown in Figure 1-, IR and IRS-2 phosphorylated and total protein levels equally increased with all concentrations of EC and CPE tested, as well as the phosphorylated and total protein levels of IRS-1 when cells were incubated with CPE. EC dosedependently increased the phosphorylated and total levels of IRS-1 (Figures 1A and 
1C). All these results suggest that EC and CPE could strengthen the insulin signalling cascade by up-regulating the early steps of this pathway.

\subsection{Effects of EC and CPE on AKT, GSK3 and GS phosphorylation}

AKT is the molecular key in mediating the metabolic effects of insulin signalling [25]. It lays downstream of PI3K and facilitates glucose uptake and glycogen synthesis in the liver [25]. To test the modulation of AKT by EC and CPE, phosphorylated and total AKT were evaluated in cell lysates by Western blot analysis. As shown in Figures 2A and $2 \mathrm{~B}$, the treatment of cells with $\mathrm{EC}$ and $\mathrm{CPE}$ for $24 \mathrm{~h}$ increased the phosphorylation of AKT with all concentrations tested. EC $(10 \mu \mathrm{M})$ showed higher levels of p-AKT than lower concentrations of EC, whereas all doses of CPE induced a similar enhancement in p-AKT values.

Since AKT directly contributes to the activity of GS [25], the effect of EC and CPE on the phosphorylated and total protein expression levels of GSK3 and GS was assayed. Western blot analysis of GSK3 and p-GSK3 proteins showed two bands corresponding to the $\alpha$ and $\beta$ isoforms. EC and CPE treatment enhanced the phosphorylated isoforms, as illustrated in Figures $2 \mathrm{~A}$ and $2 \mathrm{C}$. EC $(10 \mu \mathrm{M})$ induced the highest increase in the levels of p-GSK3 in comparison to the other doses of EC, and CPE equally enhanced the levels of p-GSK3 with all concentrations assayed, in agreement to what was observed for AKT (Figures 2A and 2B).

As shown in Figures 2A and 2D, p-GS levels decreased in the presence of EC or CPE with all concentrations tested. As it could be expected according to the previous results, CPE equally diminished the phosphorylated levels of GS and $10 \mu \mathrm{M}$ EC induced the most remarkable diminution of p-GS of all EC concentrations assayed. There was no difference in the total levels of AKT, GSK3 and GS. 


\subsection{Effects of EC and CPE on AMPK phosphorylation}

To continue the study of the potential effect of EC and CPE on key proteins of the insulin signalling, AMPK, which is a sensor of energy status for maintaining cellular energy homeostasis [5], was evaluated by analysing the total and phosphorylated levels in total cell lysates by Western blot analysis. Figure 3 illustrates that a $24 \mathrm{~h}$ treatment with EC or CPE induced an increase in AMPK phosphorylated levels. EC (5 and 10 $\mu \mathrm{M})$ showed higher levels of p-AMPK than the lowest concentration of EC, whereas CPE induced a similar activation of AMPK with all concentrations tested. The protein levels of total AMPK were not modified by EC or CPE treatment.

\subsection{Effects of EC and CPE on GLUT-2 protein levels}

The GLUT-2 transporter mediates the diffusion of glucose across the plasma membrane of the hepatocyte, maintaining intracellular glucose in equilibrium with extracellular glucose [3]. To test whether this transporter was affected by EC and CPE, HepG2 cells were incubated with the selected concentrations for $24 \mathrm{~h}$.

Treatment of HepG2 cells with any of the three concentrations of EC did not affect the expression levels of GLUT-2, and only $10 \mu \mathrm{g} / \mathrm{mL}$ CPE increased the levels of GLUT-2 after a 24 h-incubation (Figure 4).

\subsection{Effect of EC and CPE activation of AKT on hepatic gluconeogenesis}

In the liver, insulin-activated AKT inhibits the expression of PEPCK and G6Pase and, therefore, gluconeogenesis [3]. In view of the increased levels of p-AKT induced by EC and CPE, it was studied whether both substances were able to modulate the expression of a major enzyme responsible of the regulation of gluconeogenesis, such as PEPCK, as 
well as the production of glucose. To this end, HepG2 cells were exposed to a selective inhibitor of AKT (LY294002) and EC or CPE and the levels of PEPCK and the novo production of glucose were assayed. The concentrations selected for these analyses were the doses that exhibited a prominent effect on the activation of the PI3K/AKT pathway, i.e.: $10 \mu \mathrm{M}$ for $\mathrm{EC}$ and $1 \mu \mathrm{g} / \mathrm{mL}$ for $\mathrm{CPE}$.

Treatment of HepG2 cells with EC or CPE showed a comparable decrease in the expression of PEPCK (Figures 5A and 5B). LY294002 alone increased the levels of PEPCK, although these values decreased by the addition of EC and CPE (Figures 5A and 5B). LY294002 treatment decreased p-AKT levels in all cells incubated with this inhibitor, although p-AKT values were partly recovered in the presence of EC or CPE when compared to untreated cells (Figures 5A and 5C). p-AMPK and total expression of AKT and AMPK were not affected by LY294002 (Figures 5A, 5C and 5D). EC and $\mathrm{CPE}$ decreased the production of glucose (Figure 5E). In addition, the presence of the AKT selective inhibitor alone increased the hepatic glucose production, and this enhancement was less prominent in LY+EC- and LY+CPE-treated cells (Figure 5E). Conversely, LY294002 could not totally block the inhibitory effect of EC and CPE on PEPCK and glucose production, indicating that other pathways may also be involved in EC- and CPE-induced effects.

\subsection{Effect of EC and CPE activation of AMPK on hepatic gluconeogenesis}

AMPK is another known suppressor of hepatic gluconeogenesis [3]. To examine the role of AMPK on the modulation of the levels of PEPCK and the production of glucose, AMPK was blocked by a selective chemical inhibitor (Compound C) prior to the treatment with EC or CPE. As mentioned above, the concentrations selected for these 
analyses were the previously chosen $(10 \mu \mathrm{M}$ for $\mathrm{EC}$ and $1 \mu \mathrm{g} / \mathrm{mL}$ for $\mathrm{CPE})$, since they showed a prominent effect on the activation of AMPK.

As illustrated in Figures 6A and 6B, EC and CPE decreased the levels of PEPCK, and the blockage of AMPK induced a significant increase in the expression of the mentioned gluconeogenic enzyme. However, this enhancement was less pronounced in the presence of EC and $\mathrm{CPE}$ in comparison to that induced by the compound $\mathrm{C}$ alone. Treatment with compound $\mathrm{C}$ alone decreased p-AMPK levels, whereas incubation with $\mathrm{EC}$ or $\mathrm{CPE}$ and compound $\mathrm{C}$ partly recovered p-AMPK levels (Figures 6A and 6D). pAKT and total AKT and AMPK remained unaltered after incubating the cells with compound $\mathrm{C}$ (Figures 6A, 6C and 6D). In addition, compound $\mathrm{C}$ enhanced the glucose production via hepatic gluconeogenesis (Figure 6E). Similarly, the increase in glucose production was higher in compound $\mathrm{C}$-treated cells than in $\mathrm{C}+\mathrm{EC}-$ and $\mathrm{C}+\mathrm{CPE}$-treated cells (Figure 6E). However, compound $\mathrm{C}$ could not completely block the inhibitory effect of EC and CPE on PEPCK and glucose production, indicating that other pathways may also contribute to the beneficial effects of EC and CPE. 


\section{Discussion}

Flavonoids have been found to possess beneficial effects on health and have drawn attention because of their safety and accumulating evidence on their antidiabetic effects in animals and humans [2]. In the current study, we have demonstrated for the first time that EC and CPE enhanced the tyrosine phosphorylated and total IR, IRS-1 and IRS-2 levels together with an activation of the PI3K/AKT pathway and AMPK (Figure 7). We have also provided evidence on the insulin-like activity of EC and CPE, which were able to down-regulate the levels of the key gluconeogenic enzyme PEPCK and modulate the hepatic glucose production through AKT and AMPK (Figure 7). HepG2 cells are widely used for biochemical and nutritional studies as a cell culture model of human hepatocytes since they retain their morphology and most of their function in culture [26-28]. Thus, this cell line has been extensively used to study the hepatic glucose production and the modulation of the insulin pathway in vitro [27-30].

The liver plays a critical role in maintaining blood glucose concentration both through its ability to supply glucose to the circulation via glycogenolysis and gluconeogenesis in the postabsorptive state and to remove glucose from the circulation after meal ingestion [3]. However, in diabetes the gluconeogenic pathway is aberrantly activated, supplies a relatively larger amount of glucose into the circulation $[2,3]$, and there is also hepatic insulin resistance [3]. Therefore, the modulation of the mentioned targets could be beneficial for the prevention and control of this disease; in this line, natural compounds such as flavonoids could play a major role, although little investigation at the molecular level has been performed.

In the present study it is shown that EC and CPE increased tyrosine phosphorylation and total levels of IR and IRS in HepG2 cells. In concert, epigallocatechin gallate (EGCG) and naringenin attenuated high glucose-induced signalling blockage by 
reducing IRS-1 serine phosphorylation in HepG2 cells [27] and by activating IRS-1 in primary hepatocytes of mice with metabolic syndrome [31]. In addition, green tea polyphenols increased IRS-2 mRNA levels in the liver [32], as well as IR and IRS-1 and -2 levels in the myocardium of insulin-resistant rats [33]. Similarly, oligomers of a grape-seed procyanidin extract increased IR and IRS levels in preadipocytes [34]. In this line, the oligomeric structures of the extract activated the IR by interacting with and inducing its tyrosine phosphorylation [34]. ECGC and rutin stimulated the IRS2 signalling by enhancing tyrosine phosphorylation under high glucose condition on pancreatic $\beta$ cells [35], and in 3T3-L1 preadipocytes a CPE did not affect the levels of IR but it modulated its IR kinase activity via direct binding [36].

The activation of IRS-1/-2 initiates the stimulation of the PI3K/AKT pathway, which is needed for the metabolic effects of insulin in the liver and is responsible of the inhibition of GSK-3 and activation of GS [3]. In this regard, EC and CPE seemed to mimic the metabolic actions of insulin, as they increased the phosphorylated levels of AKT and GSK-3, and decreased p-GS values. Previous studies have also demonstrated the stimulation of AKT by EC and CPE in HepG2 cells [10, 22], and EC was reported to partly reverse the inhibition of AKT phosphorylation induced by high glucose levels [27]. Similarly, naringenin activated the AKT pathway in HepG2 cells [29] and green tea polyphenols increased the RNA expression levels of PI3K/AKT in the liver of insulin-resistant rats [32]. In this line, green tea polyphenols also increased the mRNA levels of GSK3 in the liver of insulin-resistant rats [32]. However, a decrease in the expression of GSK3 and an increase in the mRNA levels of GS have been reported in the myocardium of insulin-resistant rats [33]. All together indicates that polyphenols reinforced the signal pathways responsive to insulin. 
In the liver, GLUT-2 is a glucose-sensitive gene that mediates both influx and efflux of glucose across the plasma membrane [3]. In the present study, levels of GLUT-2 were induced by the highest concentration of CPE tested, whereas EC did not show any effect on the modulation of the protein levels of this transporter. Although the influence of the phenolic compounds on the GLUTs has been scarcely evaluated, especially in the liver, in agreement with the present results no effects on the mRNA GLUT-2 levels in the liver of insulin-resistant rats fed with green tea polyphenols have been reported [32]. However, it should be mentioned that, as occurs for $10 \mu \mathrm{g} / \mathrm{mL} \mathrm{CPE}$, the grape polyphenol resveratrol and the antidiabetic drugs pioglitazone and rosiglitazone, which are peroxisome proliferator-activated receptor (PPAR)- $\gamma$ agonists, were able to increase GLUT-2 expression in $\beta$-cells $[37,38]$. In this line, our results could suggest that CPE could more efficiently contribute to glucose uptake from the blood when glucose levels are postprandially elevated in comparison with EC, as described for rosiglitazone [37]. This effect has been related to the regulation of PPAR $\gamma$ for rosiglitazone [37], as well as to the activation of AKT or AMPK in diabetic animals $[39,40]$, but further studies are needed to elucidate how GLUT-2 is modulated by CPE in hepatic cells.

AMPK is an important therapeutic target for diabetes as it is one of the central regulators of cellular metabolism, which can be activated at least by two pathways: liver kinase B1 (LKB1) and $\mathrm{Ca}^{2+} /$ calmodulin-dependent protein kinase kinase (CaMMK) [5]. In the present work, the phosphorylated levels of AMPK increased after incubating HepG2 cells with EC and CPE. Interestingly, the major green tea compound EGCG has previously been shown to activate AMPK in hepatic cells via CaMMK $[23,27]$. In addition, other polyphenols such as theaflavins, naringin, anthocyanins, resveratrol and apigenin have proved to activate AMPK in the liver of mice and rats and, consequently, to modulate cellular metabolism [30, 31, 41, 42]. Similarly, other natural compounds 
such as berberine, ginsenosides obtained from ginseng and extracts from the plant Artemisia sacrorum have been demonstrated to stimulate AMPK in HepG2 cells [4346].

PEPCK is one of the major enzymes responsible of the regulation of gluconeogenesis [3]. In the present work, EC and CPE decreased PEPCK levels in HepG2 cells. In agreement with our results, other phenolic compounds such as EGCG, naringenin, catechin-rich green tea, naringin, genistein, daidzein and anthocyanins diminished the levels of this gluconeogenic enzyme in hepatic cells and mouse liver during an induced insulin-resistant situation and, consequently, reduced glucose production [23, 31, 41, 47-50].

AKT and AMPK are known to suppress the gluconeogenesis in the liver $[3,4,25]$. Suppression of hepatic gluconeogenesis by AKT-dependent insulin signalling is reduced or lost in type 2 diabetes due to insulin resistance plus a relatively insufficient insulin production [25]. In addition, activation of AMPK results in enhanced fatty acid oxidation and decreased production of glucose, cholesterol and triglycerides in the liver $[3,4]$. Thus, activation of AMPK supresses G6Pase and PEPCK and then decreases hepatic glucose production $[3,4]$. In agreement, we have shown that both kinases are involved in the modulation of PEPCK levels and the production of glucose in HepG2 cells treated with EC and CPE (Figure 7). As previously mentioned, EGCG activated AMPK and consequently inhibited hepatic gluconeogenesis via AMPK, although AKT seemed not to be involved in this process since it was not stimulated by the flavanol [23]. Similarly, naringenin did not modify AKT phosphorylation, and the incubation of the cells with LY294002 did not suppress the hepatic glucose production [48]. In addition, AMPK also mediated naringin repression of hepatic gluconeogenesis [31]. In this line, other natural compounds such as berberine, ginesenosides and an extract from 
Artemisia sacrorum supressed the hepatic glucose production and/or downregulated the levels of PEPCK via AMPK, although their effects on the mentioned parameters in the presence compound $\mathrm{C}$ were weaker than the effect showed by the natural compound alone [43-46]. Interestingly, clove extract acted like insulin in HepG2 cells by reducing PEPCK gene expression and this feature was reverted by LY294002 [51]. It has also been shown that LY294002 inhibited the expression of PEPCK, but AKT did not modulate the hepatic production of glucose via gluconeogenesis [23, 49]. Likewise, in the present study p-AMPK and p-GSK3 $\beta$ levels were increased by EC and CPE incubation. Accordingly, it has been showed that in the liver the activated form of AMPK is responsible for metabolic changes via phosphorylation of downstream substrates such as GSK3 $\beta$ and cAMP response element binding protein, which are directly or indirectly related to glucose production $[43,46]$. In this regard, EGCG promotes phosphorylation of CaMKK, and blockade of CaMKK activity prevents EGCG activation of AMPK and mitigates the inhibitory role of EGCG in hepatic gluconeogenesis [23].

As mentioned above, cocoa is a rich source of flavonoids such as (-)-EC, (+)-catechin, and procyanidins, and EC is the most abundant flavanol in the CPE employed in this study [6]. Considering that concentrations of EC in tested doses of CPE range from 13.2 $\mathrm{nM}$ (in the dose of $1 \mu \mathrm{g} \mathrm{CPE} / \mathrm{mL}$ ) to $132 \mathrm{nM}$ (in that of $10 \mu \mathrm{g} \mathrm{CPE} / \mathrm{mL}$ ) [6], and CPE effects are equivalent to those of the pure flavanol, it is reasonable to assume that EC is just one of the many bioactive substances present in CPE and that the synergic effect of phenolic compounds in foodstuffs should be taken into account, as previously shown [52].

It is worth mentioning that the range of concentrations used in the study is not far from realistic. In this regard, rats fed with EC showed plasma concentrations of EC and EC 
metabolites of about $35 \mu \mathrm{M} 1 \mathrm{~h}$ after oral administration of $172 \mu \mathrm{mol} \mathrm{EC} / \mathrm{Kg}$ body weight [53]. In humans, levels of $6 \mu \mathrm{M} \mathrm{EC}$ and $41 \mathrm{nM}$ procyanidin $\mathrm{B} 2$ have been reported after ingestion of $26 \mathrm{~g}$ cocoa [54]. Similarly, levels of $0.2-0.4 \mu \mathrm{M}$ EC have been observed after ingestion of $50 \mathrm{~g}$ [55] and $80 \mathrm{~g}$ [56] chocolate. In addition, it should not be underestimated the potential contribution of EC and flavanol metabolites to the biological activity, which is unclear at present; their evaluation will require further studies. In this regard, more accurate approaches recently used are the incubation of cultured cells with plasma obtained from volunteers consuming the molecule or food of interest [57] and the employ of a system based on co-culture of human enterocytes with human hepatocytes, which has been proved to resemble a human physiological system useful for assay the bioactivity of extracts [58].

In summary, EC and CPE possess an insulin-like activity, as they enhanced tyrosine phosphorylated and total levels of IR, IRS-1 and IRS-2 and activated PI3K/AKT pathway and AMPK at concentrations that are not toxic to hepatic cells and are reachable through the diet (Figure 7). We have also revealed a new mechanism by which EC and CPE modulate the hepatic gluconeogenesis and PEPCK expression via AKT and AMPK (Figure 7). Although further efforts are needed to define the precise role of EC and cocoa in the regulation of the insulin pathways in liver cells, a diet rich in EC and/or cocoa may be a potential chemopreventive tool useful for the management of diabetes. 


\section{Acknowledgements}

This work was supported by the grants AGL2010-17579 and CSD2007-00063 from the Spanish Ministry of Science and Innovation (MICINN). I. Cordero-Herrera is a fellow of the FPI predoctoral program of MICINN.

\section{Conflict of interest statement}

The authors have declared no conflict of interest. 


\section{References}

[1] Whiting, D. R., Guariguata, L., Weil, C., Shaw, J., IDF Diabetes Atlas: Global estimates of the prevalence of diabetes for 2011 and 2030. Diabetes Res Clin Pract. 2011, 94, 311-321.

[2] Hanhineva, K., Törrönen, R., Bondia-Pons, I., Pekkinen, J., et al., Impact of dietary polyphenols on carbohydrate metabolism. Int J Mol Sci. 2010, 11, 1365-1402.

[3] Klover, P. J., Mooney, R. A., Hepatocytes: critical for glucose homeostasis. Int J Biochem Cell Biol. 2004, 36, 753-758.

[4] Mihaylova, M. M., Shaw, R. J., The AMPK signalling pathway coordinates cell growth, autophagy and metabolism. Nature Cell Biol. 2011, 13, 1016-1023.

[5] Hardie, D. G., AMP-activated protein kinase-an energy sensor that regulates all aspects of cell function. Genes \& Develop. 2011, 25, 1895-1908.

[6] Martin, M. A., Ramos, S., Mateos, R., Granado-Serrano, A. B., et al., Protection of human HepG2 cells against oxidative stress by cocoa phenolic extract. J Agric Food Chem. 2008, 56, 7765-7772.

[7] Ramos, S., Cancer chemoprevention and chemotherapy: dietary polyphenols and signalling pathways. Mol Nutr Food Res. 2008, 52, 507-526.

[8] Granado-Serrano, A. B., Martín, M. A., Izquierdo-Pulido, M., Goya, L., et al., Molecular mechanisms of (-)-epicatechin and chlorogenic acid on the regulation of the apoptotic and survival/proliferation pathways in a human hepatoma cell line. J Agric Food Chem. 2007, 55, 2020-2027.

[9] Granado-Serrano, A. B., Martín, M. A., Haegeman, G., Goya, L., et al., Epicatechin induces NF-kB, activator protein-1 (AP-1) and nuclear transcription factor erythroid 2p45-related factor-2 (Nrf2) via phosphatidylinositol-3-kinase/protein 
kinase $\mathrm{B}(\mathrm{PI} 3 \mathrm{~K} / \mathrm{AKT})$ and extracellular regulated kinase (ERK) signalling in HepG2 cells. Brit J Nutr. 2010, 103, 168-179.

[10] Granado-Serrano, A. B., Martín, M. A., Goya, L., Bravo, L., Ramos, S., Timecourse regulation of survival pathways by epicatechin on HepG2 cells. J Nutr Biochem. 2009, 20, 115-124.

[11] Ahmad, F., Khalid, P., Khan, M. M., Rastogi, A. K., Kidwai, J. R., Insulin like activity in (-) epicatechin. Acta Diabetol Lat. 1989, 26, 291-300.

[12] Vazquez-Prieto, M. A., Bettaieb, A., Haj, F. G., Fraga, C. G., Oteiza, P. I., (-)Epicatechin prevents TNF $\alpha$-induced activation of signaling cascades involved in inflammation and insulin sensitivity in 3T3-L1 adipocytes. Arch Biochem Biophys, doi.org/10.1016/j.abb.2012.02.019. 2012.

[13] Igarashi, K., Honma, K., Yoshinari, O., Nanjo, F., Hara, Y., Effects of dietary catechins on glucose tolerance, blood pressure and oxidative status in GotoKakizaki ratas. J Nutr Sci Vitaminol. 2007, 53, 496-500.

[14] Kim, M. J., Ryu, G. R., Chung, J. S., Sim, S. S., et al., Protective effects of epicatechin against the toxic effects of streptozotocin on rat pancreatic islets: in vivo and in vitro Pancreas. 2003, 26, 292-299.

[15] Taub, P. R., Ramirez-Sanchez, I., Ciaraldi, T. P., Perkins, G., et al., Alterations in skeletal muscle indicators of mitochondrial structure and biogenesis in patients with type 2 diabetes and heart failure: effects of epicatechin rich cocoa. Clin Transl Sci. 2012, 5, 43-47.

[16] Vinson, J. A., Proch, J., Bose, P., Muchler, S., et al., Chocolate is a powerful ex vivo and in vitro antioxidant, antiatherosclerotic agent in an animal model, and a significant contributor to antioxidants in the European and American diets. $J$ Agric Food Chem. 2006, 54, 8071-8076. 
[17] Granado-Serrano, A. B., Martín, M. A., Bravo, L., Goya, L., Ramos, S., A diet rich in cocoa attenuates $\mathrm{N}$-nitrosodiethylamine-induced liver injury in rats. Food Chem Toxicol. 2009, 47, 2499-2506.

[18] Abril-Gil, M., Massot-Cladera, M., Pérez-Cano, F. J., Castellote, C., et al., A diet enriched with cocoa prevents IgE synthesis in a rat allergy model. Pharmacol. Res. 2012, 65, 603-608.

[19] Grassi, D., Desideri, G., Necozione, S., Lippi, C., et al., Blood pressure is reduced and insulin sensitivity increased in glucose-intolerant, hypertensive subjects after 15 days of consuming high-polyphenol dark chocolate. J Nutr. 2008, 138, 16711676.

[20] Hooper, L., Kay, C., Abdelhamid, A., Kroon, P. A., et al., Effects of chocolate, cocoa, and flavan-3-ols on cardiovascular health: a systematic review and metaanalysis of randomized trials. Am J Clin Nutr. 2012, 95, 740-751.

[21] Ruzaidi, A. M. M., Abbe, M. M. J., Amin, I., Nawalyah, A. G., Muhajir, H., Protective effect of polyphenol-rich extract prepared from Malaysian cocoa (Theobroma cacao) on glucose levels and lipid profiles in streptozotocin-induced diabetic rats. J Sci Food Agric. 2008, 88, 1142-1447.

[22] Martín, M. A., Granado-Serrano, A. B., Ramos, S., Izquierdo Pulido, M., et al., Cocoa flavonoids up-regulate antioxidant enzyme activity via the ERK1/2 pathway to protect against oxidative stress-induced apoptosis in HepG2 cells. $J$ Nutr Biochem. 2010, 21, 196-205.

[23] Collins, Q. F., Liu, H. Y., Pi, J., Liu, Z., et al., Epigallocatechin-3-gallate (EGCG), a green tea polyphenol, suppresses hepatic gluconeogenesis through 5'-AMPactivated protein kinase. J Biol Chem. 2007, 282, 30143-30149. 
[24] Yoon, J. C., Puigserver, P., Chen, G., Donovan, J., et al., Control of hepatic gluconeogenesis through the transcriptional coactivator PGC-1. Nature. 2001, $413,131-138$.

[25] Whiteman, E. L., Cho, H., Birnbaum, M. J., Role of Akt/protein kinase B in metabolism. TRENDS Endocrinol Metab. 2002, 13, 444-451.

[26] Brandon, E. F., Bosch, T. M., Deenen, M. J., Levink, R., et al., Validation of in vitro cell models used in drug metabolism and transport studies: genotyping of cytochrome P450, phase II enzymes and drug transporters polymorphisms in the human hepatoma (HepG2), ovarian carcinoma (IGROV-1) and colon carcinoma (CaCo-2, LS180) cell lines. Toxicol Appl Pharmacol. 2006, 211, 1-10.

[27] Lin, C. L., Lin, J. K., Epigallocatechin gallate (EGCG) attenuates high glucoseinduced insulin signaling blockade in human HepG2 hepatoma cells. Mol Nutr Food Res. 2008, 52, 930-939.

[28] Nakajima, K., Yamauchi, K., Shigematsu, S., Ikeo, S., et al., Selective attenuation of metabolic branch of insulin receptor down-signaling by high glucose in a hepatoma cell line, HepG2 cells. J Biol Chem. 2000, 275, 20880-20886.

[29] Borradaile, N. M., de Dreu, L. E., Huff, M. W., Inhibition of net HepG2 cell apolipoprotein B secretion by the citrus flavonoid naringenin involves activation of phosphatidylinositol 3-kinase, independent of insulin receptor substrate-1 phosphorylation. Diabetes. 2003, 52, 2554-2561.

[30] Lin, C. L., Huang, H. C., Lin, J. K., Theaflavins attenuate hepatic lipid accumulation through activating AMPK in human HepG2 cells. J Lipid Res. 2007, 48, 2334-2343. 
[31] Pu, P., Gao, D. M., Mohamed, S., Chen, J., et al., Naringin ameliorates metabolic syndrome by activating AMP-activated protein kinase in mice fed a high-fat diet. Arch Biochem Biophys. 2012, 518, 61-70.

[32] Cao, H., Hininger-Favier, I., Kelly, M. A., Benaraba, R., et al., Green tea polyphenol extract regulates the expression of genes involved in glucose uptake and insulin signaling in rats fed a high fructose diet. J Agric Food Chem. 2007, $55,6372-6378$

[33] Qin, B., Polansky, M. M., Harry, D., Anderson, R. A., Green tea polyphenols improve cardiac muscle mRNA and protein levels of signal pathways related to insulin and lipid metabolism and inflammation in insulin-resistant rats. Mol Nutr Food Res. 2010, 54, S14-S23.

[34] Montagut, G., Onnockx, S., Vaqué, M., Bladé, C., et al., Oligomers of grape-seed procyanidin extract activate the insulin receptor and key targets of the insulin signaling pathway differently from insulin. J Nutr Biochem. 2010, 21, 476-481.

[35] Cai, E. P., Lin, J. K., Epigallocatechin gallate (EGCG) and rutin suppress the glucotoxicity through activating IRS2 and AMPK signaling in rat pancreatic $\beta$ cells. J Agric Food Chem. 2009, 57, 9817-9827.

[36] Min, S. Y., Yang, H., Seo, S. G., Shin, S. H., et al., Cocoa polyphenols suppress adipogenesis in vitro and obesity in vivo by targeting insulin receptor. Int J Obes (London), doi: 10.1038/ijo.2012.85. 2012.

[37] Kim, H. S., Noh, J. H., Hong, S. H., Hwang, Y. C., et al., Rosiglitazone stimulates the release and synthesis of insulin by enhancing GLUT-2, glucokinase and BETA2/NeuroD expression. Biochem Biophys Res Commun. 2008, 367, 623629. 
[38] Vetterli, L., Brun, T., Giovannoni, L., Bosco, D., Maechler, P., Resveratrol potentiates glucose-stimulated insulin secretion in INS-1E beta-cells and human islets through Sirt1 dependent mechanism. J Biol Chem. 2011, 286, 6049-6060.

[39] Leclerc, I., Lenzner, C., Gourdon, L., Vaulont, S., et al., Hepatocyte nuclear factor4alpha involved in type 1 maturity-onset diabetes of the young is a novel target of AMP-activated protein kinase. Diabetes. 2001, 50, 1515-1521.

[40] Ruan, C. T., Lam, S. H., Chi, T. C., Lee, S. S., Su, M. J., Borapetoside C from Tinospora crispa improves insulin sensitivity in diabetic mice. Phytomedicine. 2012, 19, 719-724.

[41] Takikawa, M., Inoue, S., Horio, F., Tsuda, T., Dietary anthocyanin-rich bilberry extract ameliorates hyperglycemia and insulin sensitivity via activation of AMPactivated protein kinase in diabetic mice. $J$ Nutr. 2010, 140, 527-533.

[42] Zang, M., Xu, S., Maitland-Toolan, K. A., Zuccollo, A., et al., Polyphenols stimulate AMP-activated protein kinase, lower lipids, and inhibit accelerated atherosclerosis in diabetic LDL receptor-deficient mice. Diabetes. 2006, 55, 2180-2191.

[43] Yuan, H. D., Kim, Y. D., Quan, H. Y., Kim, S. J., et al., Ginsenoside Rg2 induces orphan nuclear receptor SHP gene expression and inactivates GSK3b via AMPactivated protein kinase to inhibit hepatic glucose production in HepG2 cells. Chem Biol Interact. 2012, 195, 35-42.

[44] Kim, S. J., Yuan, H. D., Chung, S. H., Ginsenoside Rg1 suppresses hepatic glucose production via AMP-activated protein kinase in HepG2 cells. Biol Pharm Bull. $2010,33,325-328$ 
[45] Zhang, M., Lv, X., Li, J., Meng, Z., et al., Sodium caprate augments the hypoglycemic effect of berberine via AMPK in inhibiting hepatic gluconeogenesis. Mol Cell Endocrinol. 2012, 363, 122-130.

[46] Yuan, H. D., Piao, G. C., An active part of Artemisia sacrorum Ledeb. suppresses gluconeogenesis through AMPK mediated GSK3 $\beta$ and CREB phosphorylation in human HepG2 cells. Biosci Biotechnol Biochem. 2011, 75, 1079-1084.

[47] Choi, M. S., Jung, U. J., Yeo, J., Kim, M. J., Lee, M. K., Genistein and daidzein prevent diabetes onset by elevating insulin level and altering hepatic gluconeogenic and lipogenic enzyme activities in non-obese diabetic (NOD) mice. Diabetes Metab Res Rev. 2008, 24, 74-81.

[48] Purushotham, A., Tian, M., Belury, M. A., The citrus fruit flavonoid naringenin suppresses hepatic glucose production from Fao hepatoma cells. Mol Nutr Food Res. 2009, 53, 300-307.

[49] Waltner-Law, M. E., Wang, X. L., Law, K., Hall, R. K., et al., Epigallocatechin gallate, a constituent of green tea, represses hepatic glucose production. J Biol Chem. 2002, 277, 34933-34940.

[50] Yasui, K., Tanabe, H., Okada, N., Fukutomi, R., et al., Effects of catechin-rich green tea on gene expression of gluconeogenic enzymes in rat hepatoma H4IIE cells. Biomed Res. 2010, 31, 183-189.

[51] Prasad, R. C., Herzog, B., Boone, B., Sims, L., Waltner-Law, M., An extract of Syzygium aromaticum represses genes encoding hepatic gluconeogenic enzymes. J Ethnopharmacol. 2005, 96, 295-301.

[52] Ramiro, E., Franch, A., Castellote, C., Perez-Cano, F., et al., Flavonoids from Theobroma cacao down-regulate inflammatory mediators. J Agric Food Chem. $2005,53,8506-8511$. 
[53] Baba, S., Osakabe, N., Natsume, M., Muto, Y., et al., In vivo comparison of the bioavailability of (p)-catechin, (2)-epicatechin and their mixture in orally administered rats. $J$ Nutr. 2001, 131, 2885-2891.

[54] Holt, R. R., Lazarus, S. A., Sullards, M. C., Zhu, Q. Y., et al., Procyanidin dimer B2 [epicatechin-(4-beta-8)-epicatechin] in human plasma after the consumption of a flavanol-rich cocoa. Am J Clin Nutr. 2002, 76, 798-804.

[55] Wang, J. F., Schramm, D. D., Holt, R. R., Ensunsa, J. L., et al., A dose-response effect from chocolate consumption on plasma epicatechin and oxidative damage. J Nutr. 2000, 130, 2115S-2119S.

[56] Rein, D., Lotito, S., Holt, R. R., C.L., K., et al., Epicatechin in human plasma: in vivo determination and effect of chocolate consumption on plasma oxidation status. J Nutr. 2000, 130, 2109S-2114S.

[57] Canali, R., Ambra, R., Stelitano, C., Mattivi, F., et al., A novel model to study the biological effects of red wine at molecular level. Br J Nutr. 2007, 97, 10531058.

[58] Castell-Auví, A., Motilva, M. J., Macià, A., Torrell, H., et al., Organotypic coculture system to study plant extract bioactivity on hepatocytes. Food Chem. $2010,122,775-781$. 


\section{Legends to figures}

Figure 1. Effect of EC and CPE on phosphorylated and total levels of IR, IRS-1 and IRS-2 in HepG2 cells after 24 h of treatment. (A) Bands of representative experiments. Densitometric quantification of (B) p-IR and total IR, (C) p-IRS-1 and total IRS-1 and (D) p-IRS-2 and total IRS-2. Protein extracts were subjected to immunoprecipitation (IP) with the anti-phospho-tyrosine (P-Tyr) antibody. The resulting immunocomplexes were analysed by Western blot (WB) with the anti-IR or IRS-1 or IRS-2 antibody. Values are expressed as a percentage relative to the control condition (means $\pm S D, n=7-9$ ). Equal loading of Western blots was ensured by $\beta$-actin. Means (for the phosphorylated or total protein levels) without a common letter differ $(P<0.05)$.

Figure 2. Effect of EC and CPE on levels of phosphorylated and total AKT, GSK3 and GS in HepG2 cells. (A) Bands of representative experiments. Percentage data of (B) pAKT/AKT, (C) p-GSK3/GSK3 and (D) pGS/GS ratios relative to controls. Values are expressed as a percentage relative to the control condition and are means $\pm S D, n=6-9$. Equal loading of Western blots was ensured by $\beta$-actin. Means without a common letter differ $(P<0.05)$.

Figure 3. Effect of EC and CPE on phosphorylated and total AMPK levels in HepG2 cells. (A) Bands of representative experiments. (B) Percentage values of pAMPK/AMPK ratio relative to the control condition (means $\pm \mathrm{SD}, \mathrm{n}=7-8$ ). Equal loading of Western blots was ensured by $\beta$-actin. Different letters over bars indicate statistically significant differences $(P<0.05)$. 
Figure 4. Effect of EC and CPE on GLUT-2 levels in HepG2 cells. (A) Bands of representative experiments. (B) Densitometric quantification of GLUT-2. Values are expressed as a percentage relative to the untreated control condition and are means $\pm \mathrm{SD}$, $\mathrm{n}=7-8$. Equal loading of Western blots was ensured by $\beta$-actin. Means without a common letter differ $(P<0.05)$

Figure 5. Effect of EC and CPE and selective inhibitor LY (LY294002) on levels of PEPCK, AKT and AMPK, and glucose production. HepG2 cells were incubated in the presence or absence of $25 \mu \mathrm{M} L Y$ for $1 \mathrm{~h}$ and later with $10 \mu \mathrm{M}$ EC or $1 \mu \mathrm{g} / \mathrm{mL}$ CPE for 24 h. (A) Bands of representative experiments. Percentage data of (B) PEPCK, (C) pAKT/AKT and (D) p-AMPK/AMPK relative to the control condition (means $\pm \mathrm{SD}, \mathrm{n}=6$ 9). Equal loading of Western blots was ensured by $\beta$-actin. (E) Glucose production was expressed as percent of control are means \pm SD of 10-15 different samples per condition. Different letters over bars indicate statistically significant differences $(P<0.05)$.

Figure 6. Effect of $\mathrm{EC}$ and $\mathrm{CPE}$ and selective inhibitor Compound $\mathrm{C}$ (Comp. C) on levels of PEPCK, AKT and AMPK, and glucose production. HepG2 cells were incubated in the presence or absence of $30 \mu \mathrm{M}$ Comp. $\mathrm{C}$ for $1 \mathrm{~h}$ and later with $10 \mu \mathrm{M} \mathrm{EC}$ or $1 \mu \mathrm{g} / \mathrm{mL} \mathrm{CPE}$ for $24 \mathrm{~h}$. (A) Bands of representative experiments. Densitometric quantification of (B) PEPCK levels, (C) p-AKT/AKT and (D) p-AMPK/AMPK. Values are expressed as a percentage relative to the control condition and are means $\pm \mathrm{SD}, \mathrm{n}=6$ 10. Equal loading of Western blots was ensured by $\beta$-actin. (E) Glucose production was expressed as percent of control are means \pm SD of 10-16 different samples per condition. Means without a common letter differ $(P<0.05)$. 
Figure 7. Schematic overview showing the EC- and CPE-induced insulin and glucose signalling pathways analysed in HepG2 cells. Sharp arrows indicate positive inputs (activation), whereas a line shows negative inputs (inhibition). 
Table 1. Effects of EC and CPE on (A) cell viability and (B) cell proliferation. Cell viability was determined as relative percent of Crystal Violet stained control cells. Cell proliferation was calculated as percentage of the relative increase over the control values of BrdU incorporated into genomic DNA. Data represent means \pm SD of 8-10 samples. Means for each antioxidant without a common letter differ, $P<0.05$.

\begin{tabular}{lcc}
\cline { 2 - 3 } & Cell viability & Cell proliferation \\
& $(\%$ of viable cells $)$ & $(\%$ of controls $)$ \\
\hline $\mathbf{C}$ & $100.5 \pm 10.1^{\mathrm{a}}$ & $100.0 \pm 7.8^{\mathrm{a}}$ \\
\hline 1 & & \\
5 & $92.2 \pm 6.3^{\mathrm{a}}$ & $100.8 \pm 9.2^{\mathrm{a}}$ \\
10 & $103.7 . \pm 5.3^{\mathrm{a}}$ & $100.2 \pm 7.8^{\mathrm{a}}$ \\
20 & $104.7 \pm 10.9^{\mathrm{a}}$ & $104.1 \pm 8.7^{\mathrm{a}}$ \\
\hline $\mathbf{C P E}(\boldsymbol{\mu g} / \mathbf{m L})$ & $108.7 \pm 7.2^{\mathrm{a}}$ & $102.4 \pm 8.2^{\mathrm{a}}$ \\
1 & & \\
\hline 5 & $95.0 \pm 4.8^{\mathrm{a}}$ & $93.2 \pm 7.5^{\mathrm{a}}$ \\
10 & $97.3 \pm 6.3^{\mathrm{a}}$ & $93.9 \pm 12.6^{\mathrm{a}}$ \\
\hline & & $97.5 \pm 13.3^{\mathrm{a}}$ \\
\hline
\end{tabular}


Figure 1

A

IR

IP: pY

IB: IR

IRS-1

IP: $p Y$

IB: IRS-1

IB: IRS-2

IP: $p Y$

IB: IRS-2

B-actin

C
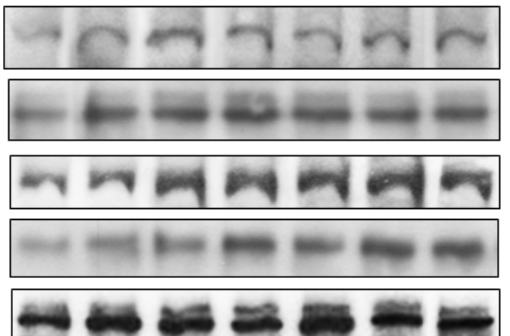

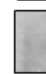

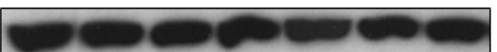

$$
\text { C } \left.\frac{1510}{E C(\mu M)} \frac{1}{\operatorname{CPE}(\mu g / m L}\right)
$$

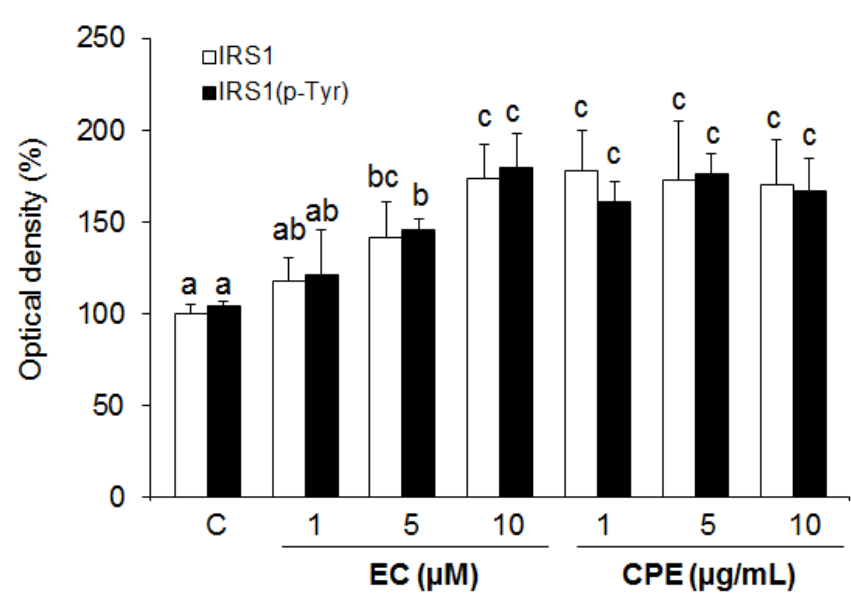

B
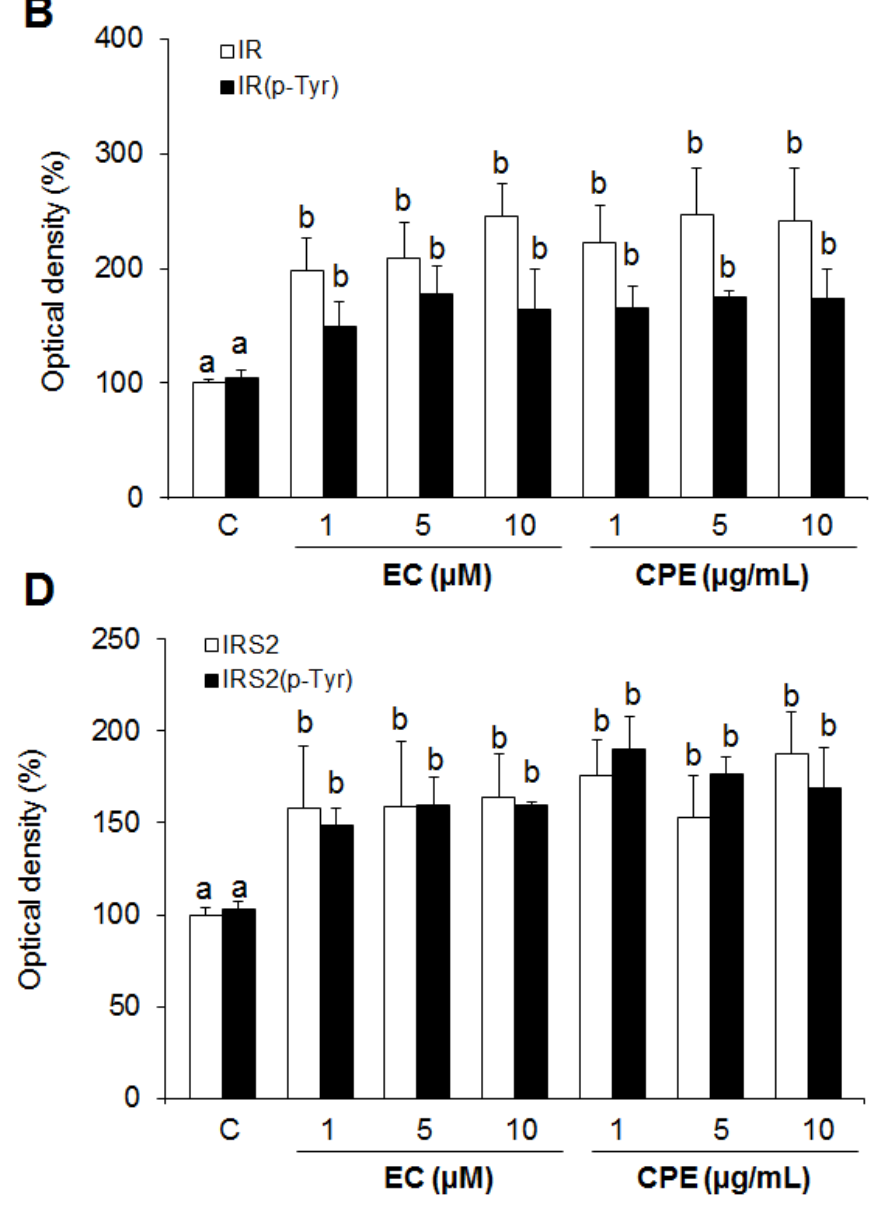
Figure 2

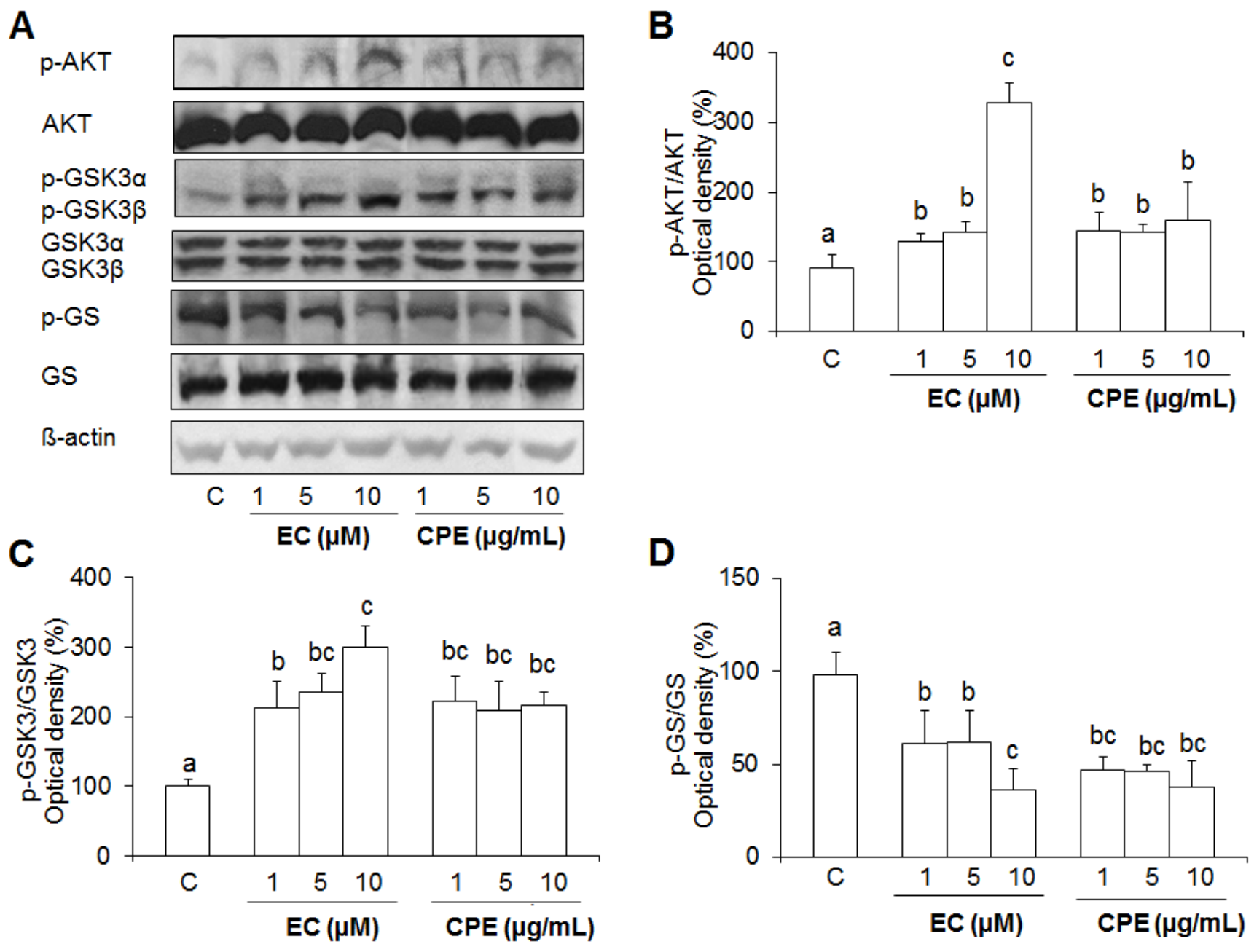


Figure 3

A

p-AMPK

AMPK

$\beta$-actin
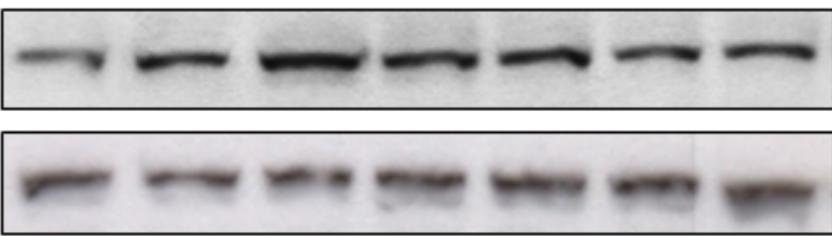

B
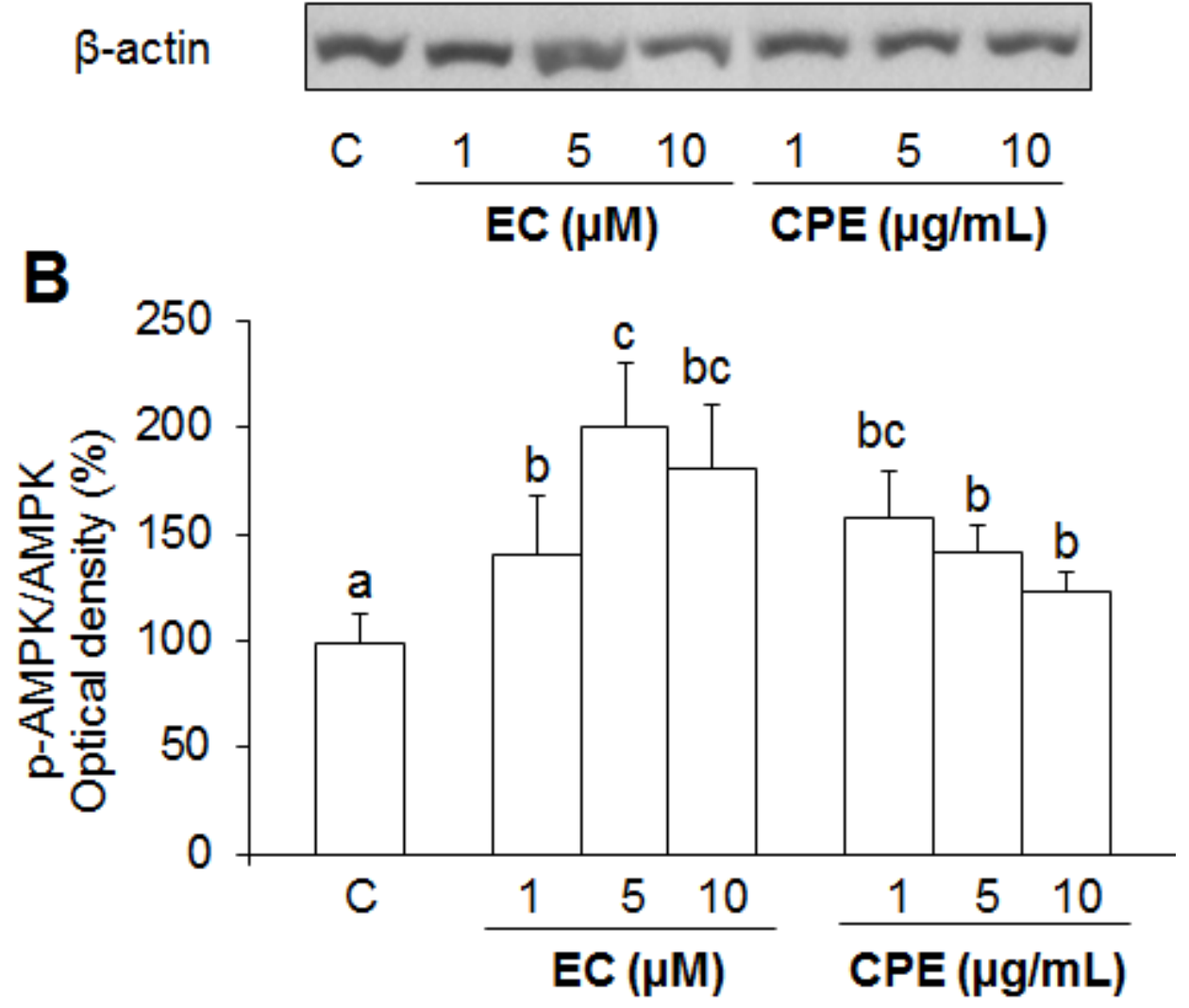
Figure 4

A

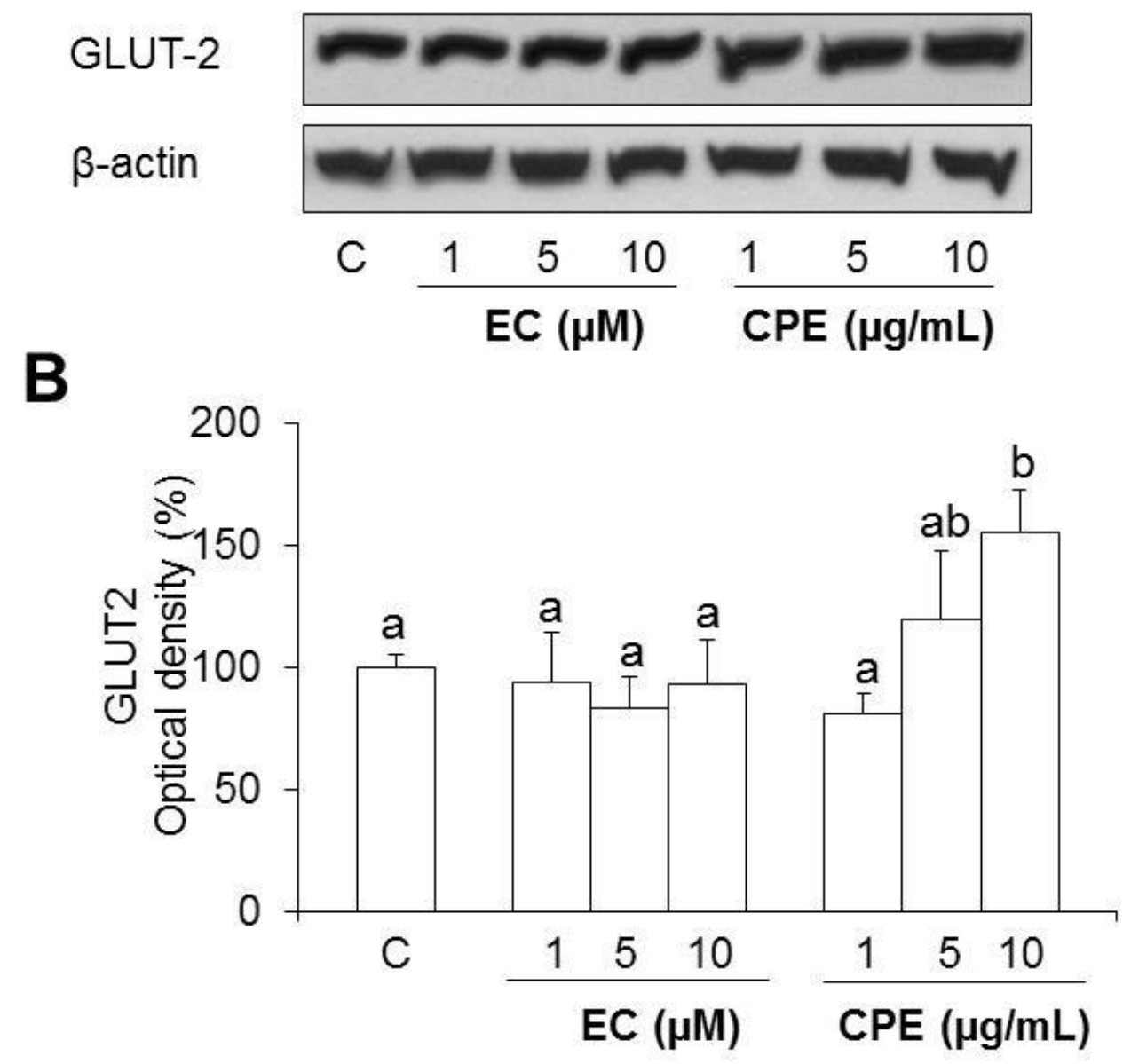


Figure 5
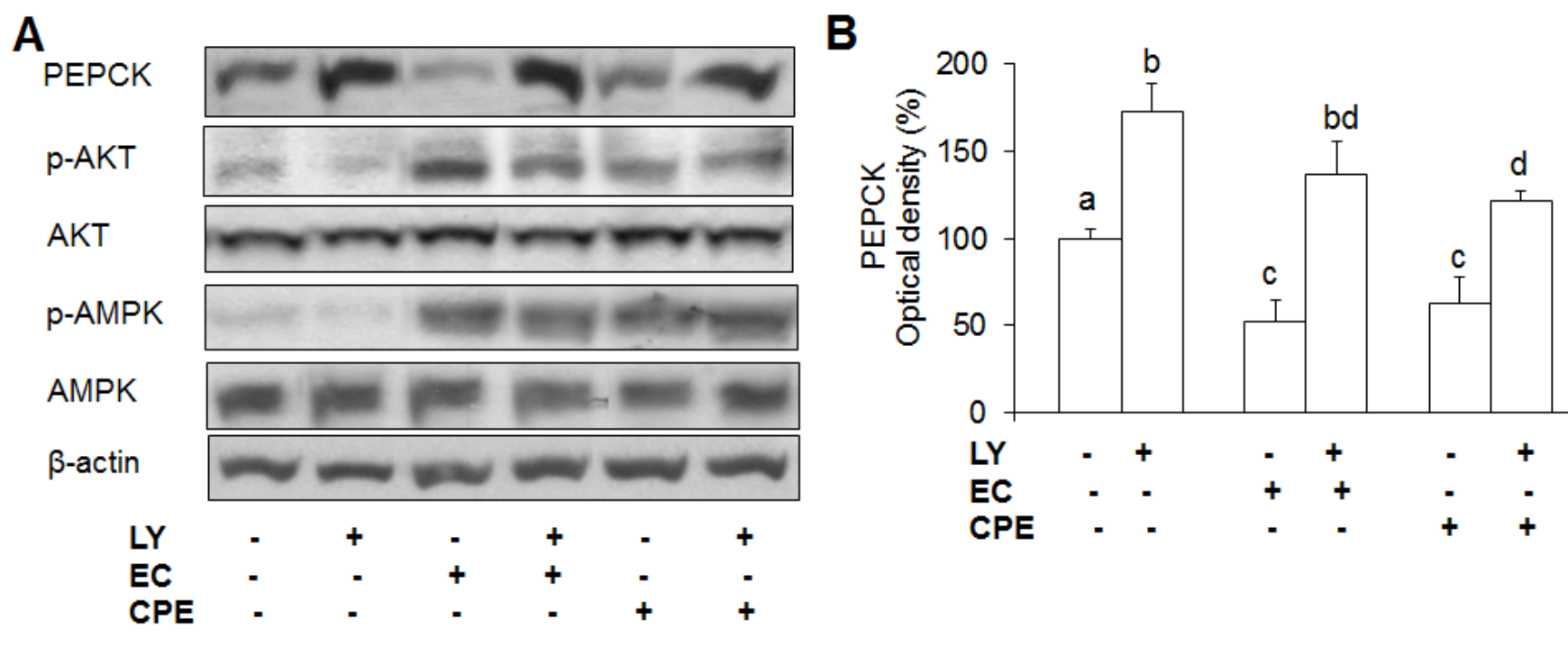

C

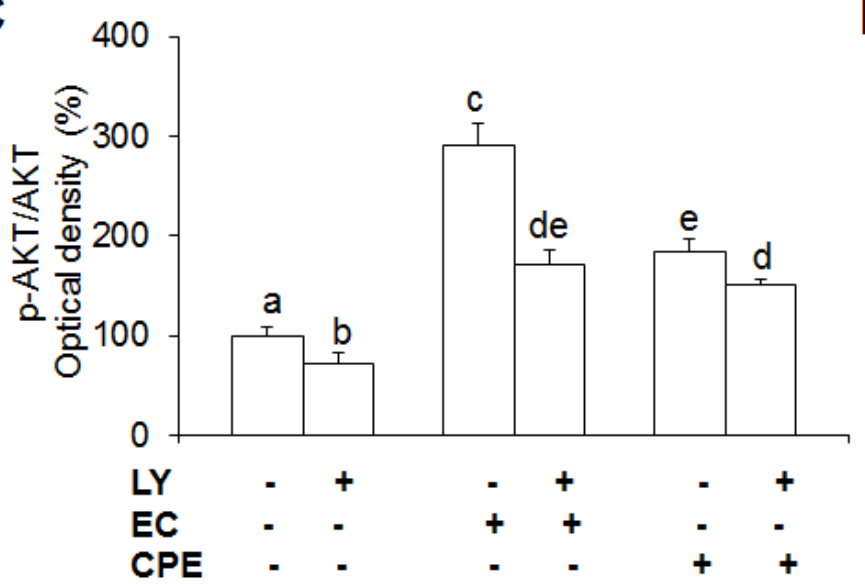

E

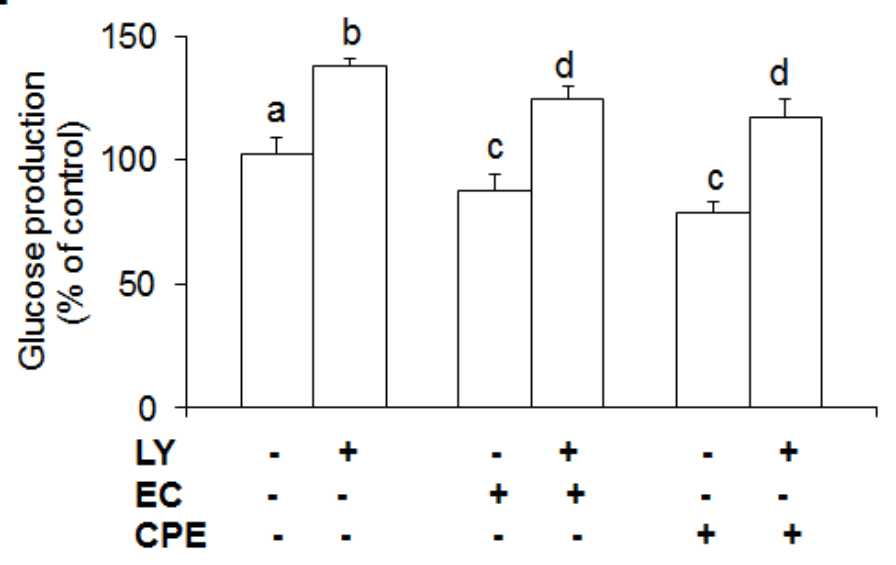

D

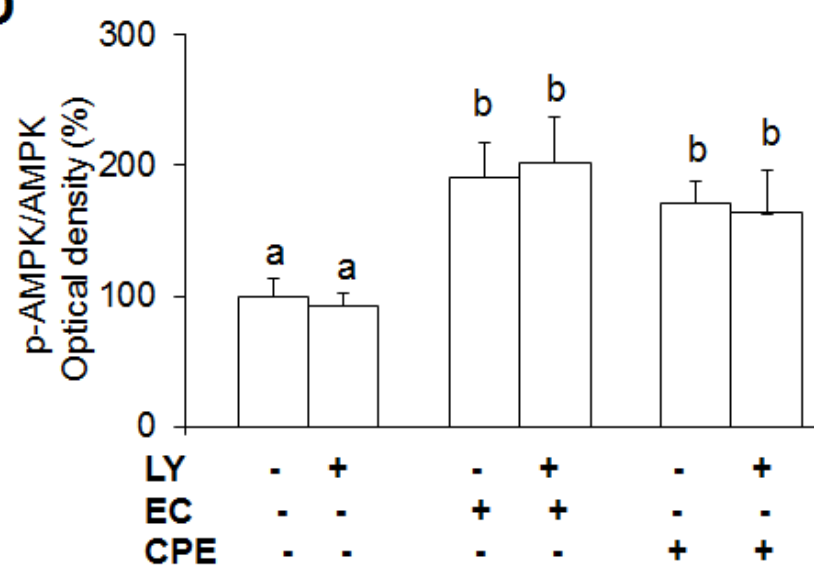


Figure 6

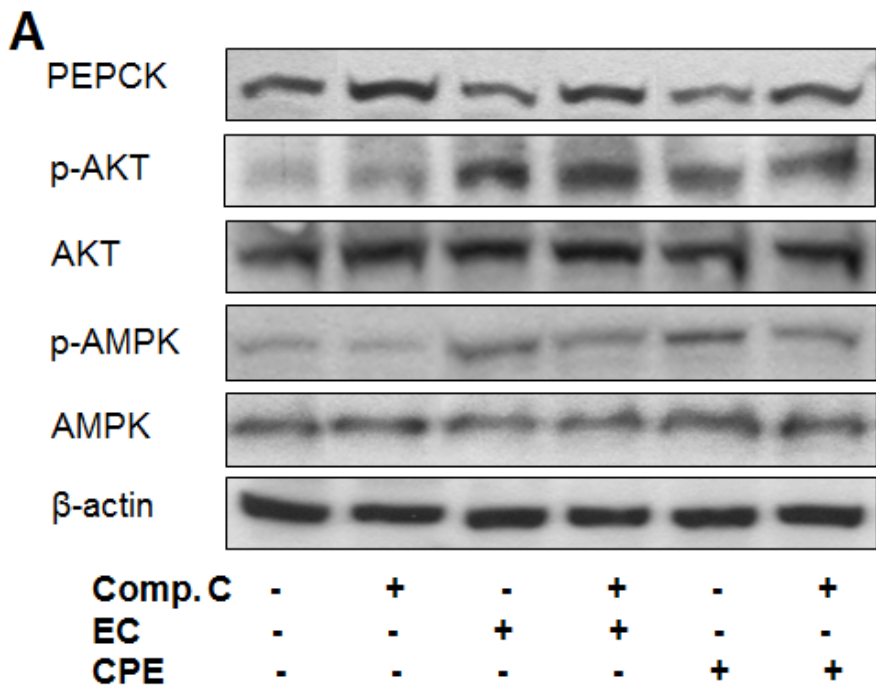

B

C

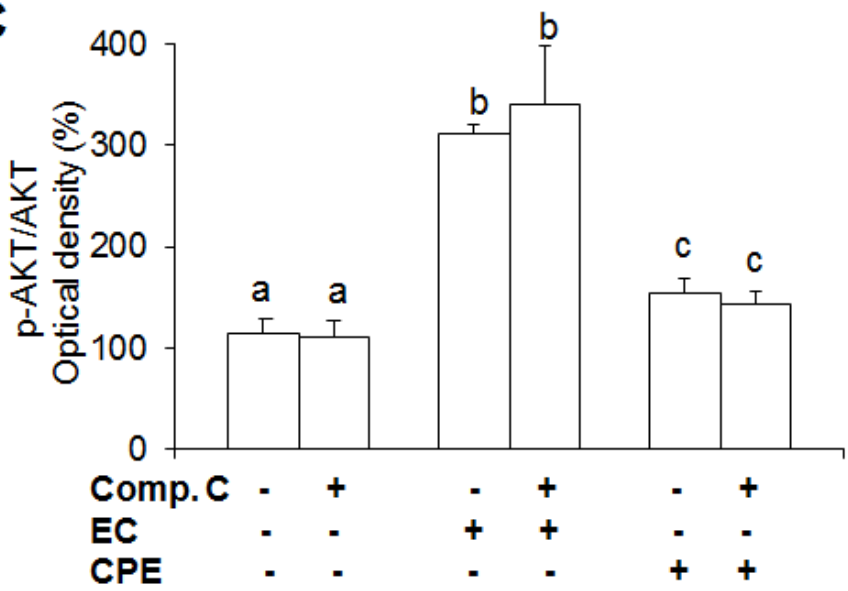

E

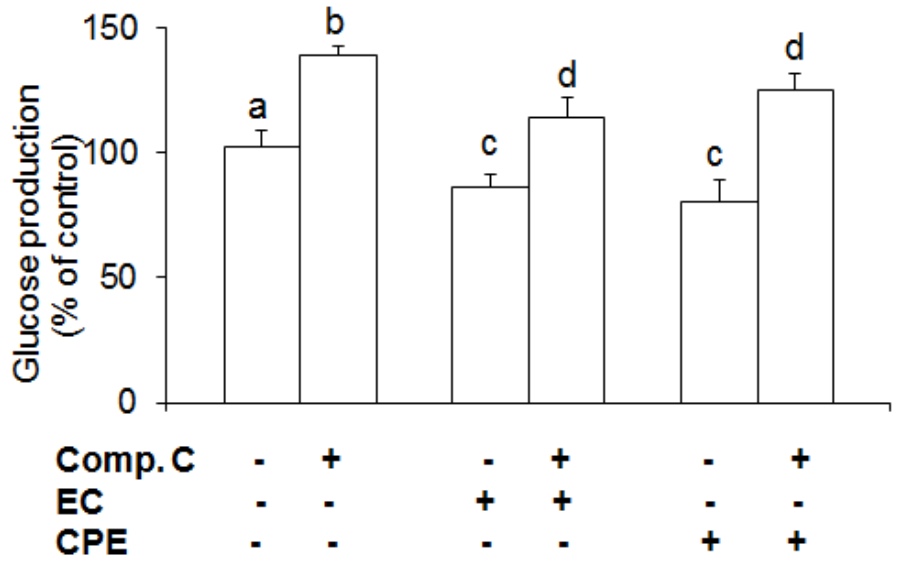

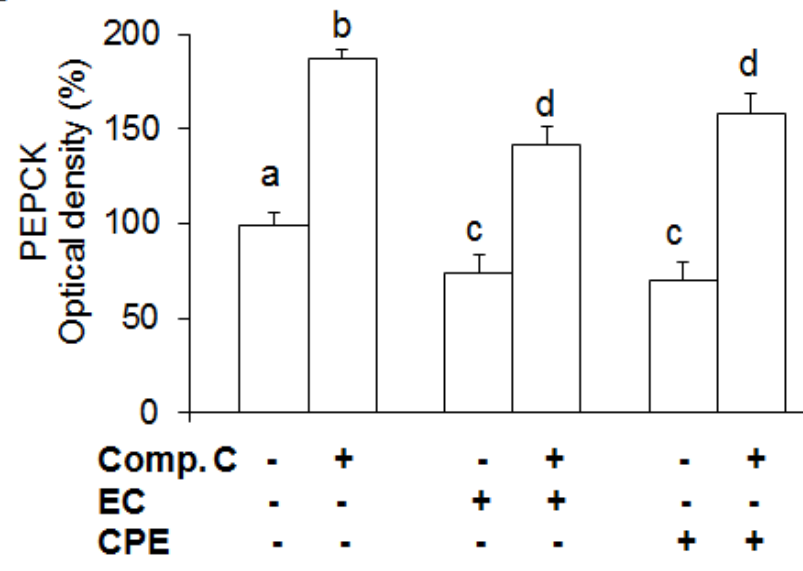

D

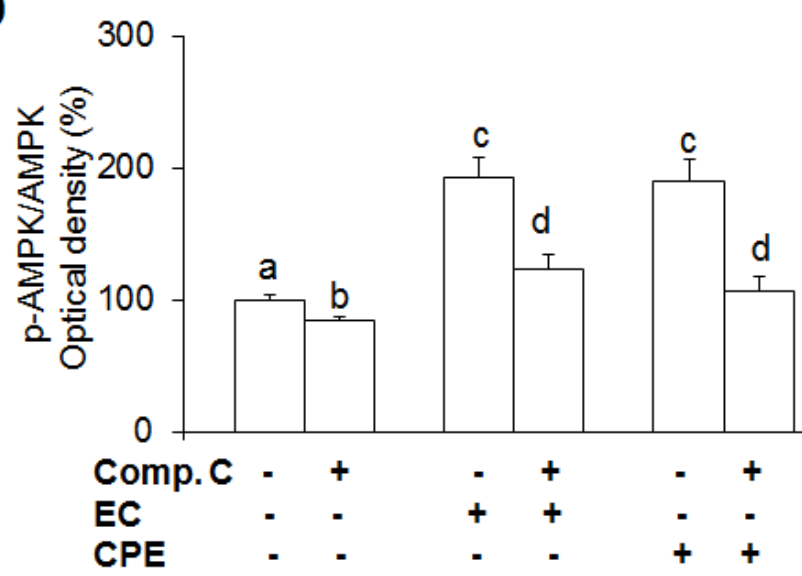


Figure 7

\section{EC/CPE}

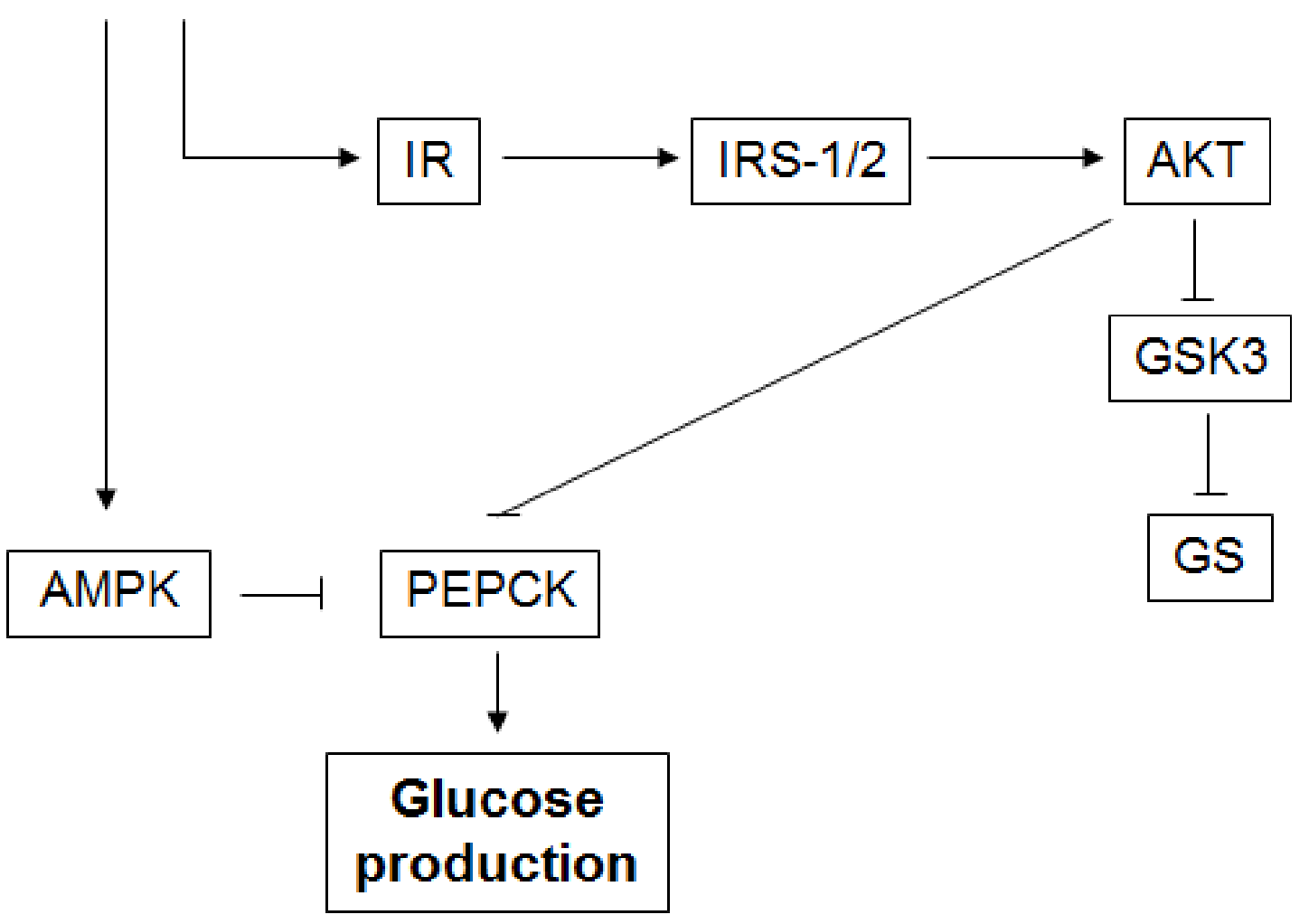

